\title{
Endoscopic Management of Aural Myiasis: Two Decades Experience
}

\section{Ranga $\mathrm{RK}^{1 *}$, Anand $\mathrm{A}^{2}$, Yadav SPS ${ }^{3}$, Malik $\mathrm{P}^{4}$ and Goel $\mathrm{A}^{5}$}

${ }^{1}$ Director, Bharat ENT \& Endoscopy Hospital, India

${ }^{2}$ Resident, Department of Otorhinolaryngolgy, K.L.E. Academy of Higher Education \& Research, India

${ }^{3}$ Sr. Professor, Pt. B.D. Sharma Medical University, India

${ }^{4}$ Resident, Pt. B.D. Sharma Medical University, India

${ }^{5}$ Professor, Department of ENT, F.H. Medical College, India

*Corresponding author: Rupender K Ranga, Director, Bharat ENT \& Endoscopy Hospital, Rohtak Gate- Bhiwani, Haryana 127021, India, Email: bharatentbwn@gmail.com, rupenderent@yahoo.co.in

\section{Abstract}

Background: The present study was undertaken to compare the efficacy of otoendoscopic removal with conventional techniques in aural myiasis patients.

Methods: The three hundred and thirty eight, aural myiasis patients in study group were treated using Hopkine rigid otoendoscope, the visible crawling caudal end of maggots was grasped with forceps \& removed. Rests were identified from crawling movements or the visible caudal end buried in EAC and middle ear cavity and removed. Complete maggots clearance of ear cavity from EAC to middle ear cavity was done and same was repeated on other side if needed. Equal number of patients were treated using head light.

Results: The mean age in two groups was 55.5 years (range 02-68) in aural myiasis patients. There were $56.5 \%$ males and $43.5 \%$ females. Mean duration of aural symptom in both groups was 2 days. Endoscopically mean number of 42 maggots (range-10-62) were removed in first sitting as compared to conventional technique where mean of 28 (range 10-48) maggots were removed $(\mathrm{p}<0.001)$. The mean duration of endoscopic treatment was 2 days whereas in control group it was 6 days. The difference was statistically significant $(\mathrm{p}<0.001)$.

Conclusion: Otoendoscopic procedure is superior to the conventional extraction method for removal of aural maggots. The larvae located in deep and inaccessible areas can be identified and removed easily. The disease was controlled in shorter time and ensures less damage to the middle ear structures.

Keywords: Aural Myiasis; Otoendoscope; Middle ear 


\section{Otolaryngology Open Access Journal}

Abbreviations: CSOM: Chronic Otitis Media; ASOM: Acute Supurative Otitis Media; MRM: Modified Radical Mastoidectomy.

\section{Introduction}

Aural myiasis, a common otorhinolaryngological clinical entity in tropical counties is becoming rare due to economical development and improved hygiene. It is an opportunistic parasitic infestation of human as well as animals caused by house fly larvae (maggots) [1]. Aural myiasis involves infestation of external ear, middle ear or both. This can be classified as accidental, facultative (opportunistic) or obligate [2]. There are many factors responsible for myiasis like low socioeconomic status, immunocompromised state, mental retardation, neglected chronic otitis media (CSOM) and unhygienic living conditions. The misery is generally associated with trauma, wounds and ulcerative lesions of skin and mucosa [3]. Although, myiasis is a self-limiting diseases, however, if not treated it may lead onto fatal complications like intracranial penetration.

Aural myiasis is accidental aural infestation. Many species of dipterous flies among the genera chrysomyia have been reported to be the most important obligatory myiasis producers among human and animals [4]. The distribution of aural myiasis is worldwide, however, more prevalent in tropical and subtropical countries. Severity of myiasis depends on location of infestation, type of lesions and tissue inflammation. The maggots cause extensive necrosis, sloughing \& destruction of intraaural tissue which reach to deep and inaccessible areas. In such a situation complete removal of maggots is difficult by manual extraction and several sittings may be required. To overcome this problem aural endoscope is being used for removal of maggots under direct vision. The maggots located in deep and inaccessible areas of middle ear can be approached more easily by endoscopic procedure. The disease is controlled in shorter periods of time and in a fewer sittings, quick and complete eradication of myiasis is possible before the maggots cause irreparable damage to the external, middle ear and adjacent tissues [5]. The study was conducted in aural myiasis patients to compare the efficacy of otoendoscopic with conventional removal techniques using head light.

\section{Material and Methods}

The present prospective study was conducted in three hundred and thirty eight consecutive patients of either sex in age group of 2 to 68 years suffering from aural myiasis during 2000- 2020 usually in months of August- October. The patients with aural myiasis presented with aural bleeding, earache, ear discharge, tinnitus, hearing loss, aural fullness, foreign body sensation and vertigo. There was history of habitual sleeping in streets in majority of cases. All patients were inquired domestic hygienic conditions. Presence of predisposing conditions like acute supurative otitis media (ASOM), chronic supurative otitis media (CSOM), modified radical mastoidectomy (MRM) and aural malignancy was ascertained. In all patients otorhinolaryngological examination was done and otoscopic examination revealed crawling live maggots on external auditory canal (Figure 1). Preoperatively routine investigations like $\mathrm{Hb}, \mathrm{BT}$, CT, Blood sugar, Blood urea, ECG, complete urine examination and X ray mastoid lateral view were carried out. Three to six hours fasting was ensured before endoscopy especially in cases where general anesthesia was required. Informed consent was obtained in writing. The patients were randomly assigned to two groups using a periodic random number. Group 1 patients were treated by otoendoscopic removal and group 2 by conventional method under head light.

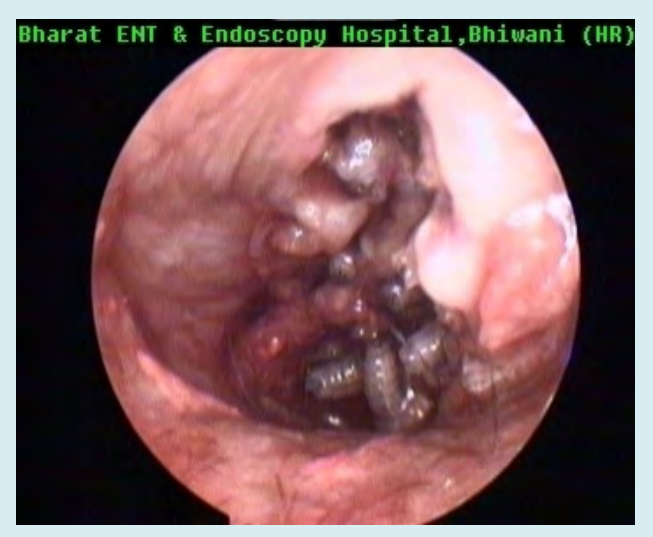

Figure 1: Photograph showing endoscopic intra aural view of maggots.

In the study group 296 patients were operated under local anesthesia after xylocaine sensitivity. Premedication with pentazocin $30 \mathrm{mg}$, promethazine $25 \mathrm{mg}$ and atropine 0.4 mg intramuscular was given half an hour prior to operative procedure. External auditory canal was anaesthetized with cottonoids soaked in 4\% Lignocaine for about 15-20 minutes. Forty two patients operated under general anesthesia. Patient was made to lie down in supine position with operated ear tilted towards surgeon. External aspect of ear was cleaned $\&$ draped. Auricular area was in filtered with $2 \%$ xylocaine with adrenaline (1: 200000). Hopkins rigid otoendoscope was introduced and the larvae buried in necrotic material were identified with their crawling movements and removed one by one by grasping with Alligator's forceps (Figure 2). Complete clearance of external auditory canal and middle ear cavity was done. After 24 hours same procedure was repeated and clearance of maggots as well as necrotic material was performed. 


\section{Otolaryngology Open Access Journal}

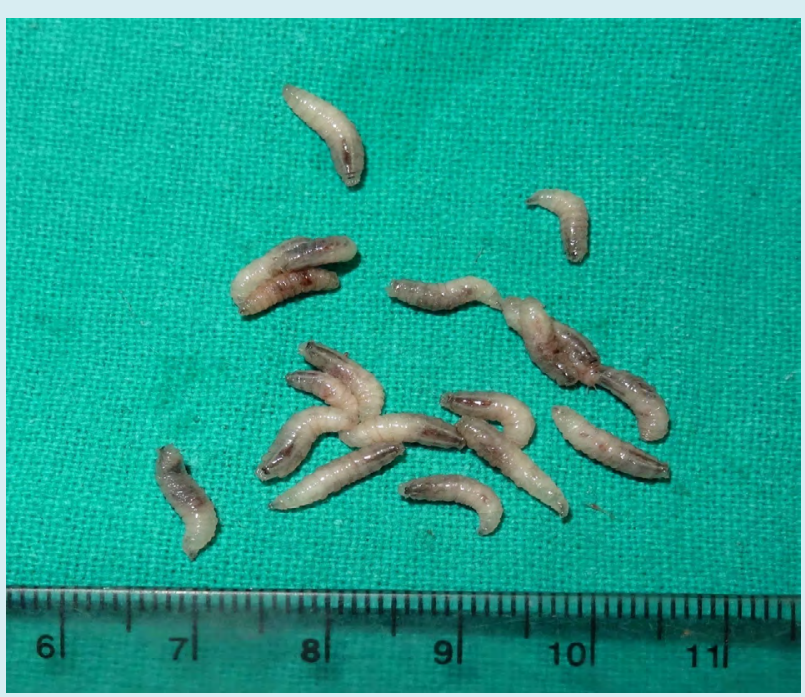

Figure 2: Photograph showing maggots after removal.

Post operatively oral co- amoxiclav according to age \& body weight in appropriate doses to prevent infections was given for10 days. Ear drops containing Prednisolone acetate $0.5 \%$, Chloramphenical 5\%, Glaccial acetic acid 3\%, Benzocaine $3 \%$ and Benzyl alcohol $2 \%$ was instilled for two weeks. At the end of one week follow-up endoscopic examination was carried out and dead maggots if any were removed.

The control group was treated with local instillation of turpentine oil and intermittently maggots were picked up manually under headlight from aural cavity with the help of Alligator forceps in 5-7 sittings. External auditory canal irrigated with normal saline and concomitant suction was performed in all patients. Post- operative treatment was similar to group 1.

\section{Results}

The mean age in study group was 56.4 years (range 0268) and in control group it was 54.6 (range 02- 68). In study group of 338 cases there were 194 (57.39\%) males and 144 (42.61\%) females, whereas in control group of 338 patients, 188 were (55.63\%) males and 150 (44.37\%) females (Table $1)$.

\begin{tabular}{|c|c|c|c|c|c|}
\hline \multirow{2}{*}{ Group } & \multirow{2}{*}{ Number } & \multicolumn{2}{|c|}{ Age (in years) } & \multicolumn{2}{|c|}{ Sex } \\
\cline { 2 - 6 } & & Mean & Range & Male & Female \\
\hline 1) Study & 338 & 56.4 & $02-68$ & $194(57.39 \%)$ & $144(42.61 \%)$ \\
\hline 2) Control & 338 & 54.6 & $02-68$ & $188(55.63 \%)$ & $150(44.37 \%)$ \\
\hline
\end{tabular}

Table 1: Age \& sex distribution of two groups of patients.

Mean duration of aural symptom in study group was 2 days, 218 (64.49\%) being on right ear, 98 (28.99\%) on left side and $22(60.52 \%)$ bilateral. In control group it was also 2 days, 198 (58.58\%) being on right, 116(34.32\%) on left side and 24(7.2\%) bilateral. Duration of symptoms in ASOM was 4-6 days (mean 5 days), CSOM 2 months- 25 years ( mean 13.5 Years), operated cases MRM were from 4 months- 5 years (mean 3.5 Years).Complaining symptoms like- otalgia (100\%), aural malodor (100\%), foreign body sensation (100\%), blood stained discharge (100\%), aural fullness (100\%), maggots in EAC (80\%), hearing loss (70\%), aural itching (70\%), tinnitus (65\%) and vertigo (40\%) were reported. In the study group 92 (27.22\%) were suffering from ASOM, 220 (65.09) CSOM and 26 (7.69\%) MRM. In control group ASOM 80 (23.57\%), CSOM 226 (66.86\%) and MRM 32 (9.47\%).

In study group the mean numbers of removed maggots was 42 (range-10-62), whereas in conventional technique (Control group) it was 28 (range 10-48) at first sitting. The mean duration of endoscopic treatment was 2 days, whereas in control it was 6 days. The difference in mean values of two samples was statistically significant between treatment period $(2 \mathrm{v} / \mathrm{s} 6$ days $)(\mathrm{p}<0.001)$ and numbers of removed maggots $(42 \mathrm{v} / \mathrm{s} 28)$ in first sitting $(\mathrm{p}<0.001)$

\section{Discussion}

The word myiasis is derived from Greek word 'Myia' meaning fly. Female flies are attracted to odoriferous suppurating lesions; the eggs are deposited on the surface of external auditory canal (Figure 3). The middle ear cavity is contaminated by blood or mucus discharge present in neglected cases of supurative otitis media [2]. These eggs can be transferred to other site by patient's own fingers due to itching and poor hygienic habits. On hatching, the maggots penetrate deep into the tissue aided by their sharp oral hooks and anchoring inter-segmental spines which scrape away the tissue and lacerate the fine blood vessels, while feeding. During feeding on necrotic or living tissue the caudal ends of the maggots with their blackish peritremes remains visible in the external auditory canal, enabling the larvae to breathe [4]. This visible caudal end of maggots was easily visualized and grasped during endoscopy, hence more maggots could 


\section{Otolaryngology Open Access Journal}

be removed especially in first sitting in the present study.

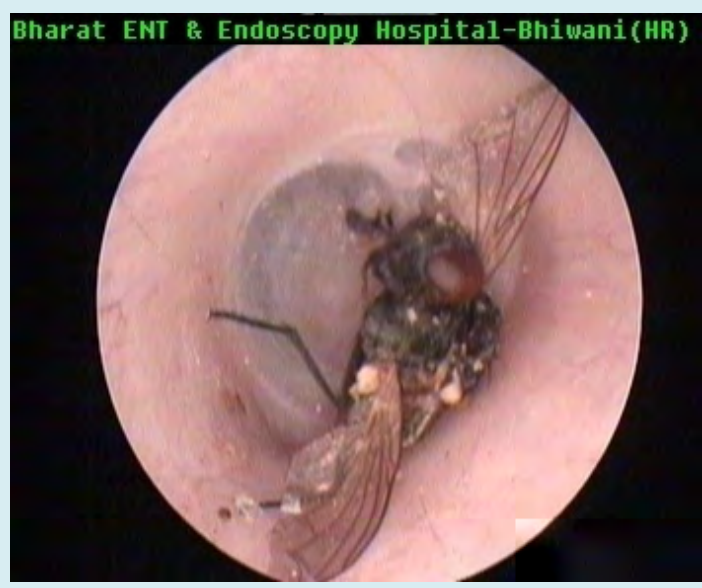

Figure 3: Photograph showing endoscopic intra aural view of fly.

Infestation is commonly implicated to larvae of Chrysomyia bezziana, a cause of obligatory myasis among human and animals in the nose, ear, face, gums and serous cavities [6]. The predisposing factors include poor hygienic condition, especially with underlying diseases like atrophic rhinitis, leprosy, diabetes with purulent sinus disease, midline granuloma, malignancy and syphilis involving nose [2,7]. Progressive necrosis of tissue continues which is associated with larval growth and invasion until a large cavernous lesion is formed, where the larvae aggregate and remain active. Hemorrhage from the lesion may be severe and surrounding tissue becomes tense, edematous and emits characteristic pungent odour. Some myiasis cause severe pain, however, carcinomatous lesion or radiotherapy induced radionecrosis destroy sensory nerve endings which may further be destroyed by maggots during the process of invasion, hence there may be no pain. Injury to external auditory canal and middle ear structures by maggots may lead to deafness, meningitis or even death [8].

In our study the mean age was $56.4 \& 54.6$ years in two groups which were from rural background and poor low hygienic status in study as well as control group. Supurative otitis media attract flies to lay eggs. In the month of AuguestOctober there is hot and humid environment at the place of study and this age group sleep either in street or in the fields where the flies gets opportunity to enter in external auditory canal to complete their reproductive cycle. In one sitting one fly lays about 200 eggs which hatch in larvae within 24 hours [9]. However, lower number is due to incomplete hatching or removal of eggs by fingers due to itching [10] as was also observed in the present study also. Mean duration of aural symptom in both groups was 2 days. The process of conversion of eggs into larvae takes 24 hours and tissue destruction \& symptoms start later on [9], hence time of presentation was same in both the groups. Right ear was affected more than left, may be due to tendency to sleep in right lateral position or putting the finger in right ear as the population is right handed at the place of study. Single fly can't lay eggs in two ear, however, eggs may be transported by finger.

In our study the complaining symptoms likeotalgia $(100 \%)$, aural malodor $(100 \%)$, foreign body sensation(100\%), blood stained discharge $(100 \%)$, aural fullness (100\%), maggots in EAC (80\%), hearing loss (70\%), aural itching (70\%), tinnitus (65\%) and vertigo (40\%) were reported. Reported clinical symptoms were consistent with symptoms of earlier workers. We performed otoendoscopic examinations in all patients and live crawling movements of maggots on external auditory canal were noted which was reported by earlier study [8].

Acute otitis media which is caused by viruses and sometimes bacteria, if not treated adequately, it causes acute supurative otitis media with blood, fluid and pus discharge. Chronic supurative otitis media is long standing chronic inflammation of middle ear and mastoid cavity along with perforated tympanic membrane with or without cholesteotoma, presenting with foul smelling purulent ear discharge. Operated cases of MRM are also prone to fungal infection and otitis extena. All such condition attracts the flies to complete their reproductive cycle [10] as were the cases in the present study.

Ranga, et al. reported that the larvae release toxins to destroy the host tissue. Proteolytic enzymes released by the surrounding bacteria decompose the tissue and the larvae feed on this rotten tissue [11]. The infected tissue frequently releases foul smelling discharge. As the interaction of toxin or enzyme released by the larvae-bacteria can also cause bony erosion of skull bone structures which may cause meningitis. Treatment comprises systemic and local measures. Systemic treatment includes broad-spectrum antibiotics such as ampicillin and amoxycillin especially when the wound is secondarily infected. Topical treatment consists of application of turpentine oil, mineral oil, ether, chloroform, ethyl chloride, mercuric chloride, creosote, saline, systemic butazolidine or thiobendazole for removal of the larvae $[3,6,7]$.

The larvae are photophobic and prefer to hide in deepest part of aural cavity even in Eustachian tube [10]. In control group local application of turpentine oil was effective in killing the maggots which were removed with forceps, however, some larvae get suffocated and come out of the external auditory canal. All maggots can't be removed in 


\section{Otolaryngology Open Access Journal}

single sitting as the larvae try to hide in deeper site especially when head light is used, hence complete clearance requires many sittings $[8,9]$ as was also observed in the control group of present study.

Otoendoscopy is performed to remove crawling maggots by picking up with Alligator's forceps under direct vision from aural cavity to shorten the duration of treatment. Earlier workers reported that larvae cause extensive necrosis, sloughing and destruction of skin of EAC, middle ear structures, Eustachian tube and deep inaccessible areas of the middle ear cavity $[10,12]$. In such a situation removal of maggots is difficult by manual extraction and several sittings are required [4]. Meticulous clearing of debris in postoperative period is necessary for good results which can easily be achieved by otoendoscopy $[7,12,13]$. The patients in our study who consented were subsequently treated with tympanoplasty.

\section{Conclusion}

In conclusion otoendoscopic procedure was found to be superior to the conventional method for removal of maggots. The disease was controlled in shorter time i.e. in couple of sittings. Thus quick and complete eradication of myiasis is possible before the maggots cause irreparable damage to the skin of EAC, middle ear \& surrounding structures.

\section{References}

1. Srinivasa V, Arivazhagan GB, Balu KG, Kayarkar D (2019) Maggots in the ear- a case series. Tropical J Ophthalmol Otolaryngol 4(1): 30-34.

2. Rana AK, Sharma R, Sharma VK, Mehrotra A, Singh R (2020) Otorhinolaryngological myiasis: The problem and it's presentation in the weak and forgotten. Ghana Med J 54(3): 173-178.
3. Mengi E, Demirhan E, Arslan IB (2014) Aural myiasis: case report. North Clin Istanb 1(3): 175-177.

4. Arora S, Sharma JK, Pippal SK, Sethi Y, Yadav A (2009) Clinical etiology of myiasis in ENT: a reterograde period - interval study. Braz J Otorhinolaryngol 75(3): 356-361.

5. Mohammed T, Islam MA, Islam MA, Lutfur Rahman ASM, Chowdhury NH, et al. (2020) Myiasis of middle ear and Eustachian tube in a neglected child: A case report. Otolaryngol Open Access J 5(2): 1-3.

6. Sood VP, Kakkar PK, Wattal BL (1976) Myiasis in otorhinolaryngology with entomological aspects. J Laryngol Otol 90(4): 393-399.

7. Singh I, Gathwala G, Yadav SPS, Wig U, Jakhar KK (1993) Myiasis in children: The Indian perspective. Int J Pediatr Otorhinolaryngol 25(1-3): 127-131.

8. Yuca K, Caksen H, Sakin YF, Yuca SA, Kiris M, et al. (2005) Aural myiasis in children and literature review. Tohoku J Exp Med 206(2): 125-130.

9. Ranga RK, Yadav SPS, Swati V, Ashiya G (2016) Tracheal myiasis: Case report. Otolaryngol Open Access J 1(3): 1-3.

10. Hatten K, Gulleth Y, Meyer T, Eisenman DJ (2010) Myiasis of the external and middle ear. Ann Otol Rhinol Laryngol 119(9): 436-438.

11. Ranga RK, Yadav SPS, Goyal A, Agrawal A (2013) Endoscopic management of nasal myiasis: A 10 years experience. Clin Rhinol: An Int J 6(1): 58-60.

12. Mishra A, Shukla GK, Bhatia N (2000) Aural foreign bodies. Indian J Pediatr 67(4): 267-269.

13. Malik P, Sinha V, Jha S, Swani J (2019) A clinico- etiological study of aural myiasis. Indian J Otol 25(4): 180-183. 